2014-03-29

\title{
Improved Protocols for Vibrational Spectroscopic Analysis of Body Fluids
}

\author{
Franck Bonnier \\ Technological University Dublin, Franck.Bonnier@tudublin.ie \\ François Petitjean \\ Matthew Baker \\ University of Central Lancashire
}

See next page for additional authors

Follow this and additional works at: https://arrow.tudublin.ie/biophonart

Part of the Diagnosis Commons, and the Physics Commons

\section{Recommended Citation of Biophotonics, 7, pp.167-179. DOI: 10.1002/jbio.201300130 \\ This Article is brought to you for free and open access by the DIT Biophotonics and Imaging at ARROW@TU Dublin. It has been accepted for inclusion in Articles by an authorized administrator of ARROW@TU Dublin. For more information, please contact arrow.admin@tudublin.ie, aisling.coyne@tudublin.ie, gerard.connolly@tudublin.ie. Funder: SFI}

Bonnier, F. et al (2014) Improved Protocols for Vibrational spectroscopic analysis of body fluids, Journal 


\section{Authors}

Franck Bonnier, François Petitjean, Matthew Baker, and Hugh Byrne

This article is available at ARROW@TU Dublin: https://arrow.tudublin.ie/biophonart/11 
Improved Protocols for Vibrational spectroscopic analysis of body fluids Franck Bonnier $^{1}$, François Petitjean ${ }^{2}$, Matthew J. Baker ${ }^{3}$, Hugh J. Byrne ${ }^{1}$ 1. Focas Research Institute, Dublin Institute of Technology (DIT), Camden Row, Dublin 8, Ireland

2. Haute Ecole Léonard de Vinci, Institut Paul Lambin, Brussels, Belgium

3. Centre for Materials Science, Division of Chemistry, University of Central Lancashire (UCLan), Preston PR1 2HE, UK

*Corresponding Author: Franck Bonnier,

Focas Research Institute, Dublin Institute of Technology,

Kevin Street, Dublin 8, Ireland.

E mail address: fbonnier@ dit.ie

Ph: +35314027917

Fax: +35314027904 


\begin{abstract}
The applications of vibrational spectroscopy to the examination of human blood serum are explored. Although FTIR spectra can be recorded in aqueous solutions at (gelatin) concentrations as low as $100 \mathrm{mg} / \mathrm{L}$, the high-wavenumber region remains obscured by water absorption. Using Raman spectroscopy, high quality spectra of gelatine solutions as low as $10 \mathrm{mg} / \mathrm{L}$ can be achieved, also covering the highwavenumber regions. In human serum, spectral profiles are weak and partially obscured by water features. Dried deposits are shown to be physically and chemically inhomogeneous resulting in reduced measurement reproducibility. Concentration of the serum using commercially available centrifugal filter devices results in an improvement in the spectral intensity and quality. Additionally, in Raman spectroscopy, reduced background and significantly enhanced signal collection is achievable by measurement in an inverted geometry. The improved protocols for spectroscopic measurement of human serum are applicable to a range of bodily fluids and should accelerate potential clinical applications.
\end{abstract}

Keywords: Infrared spectroscopy, Raman spectroscopy, bodily fluids, human serum, centrifugal filtration 


\section{Introduction}

Vibrational spectroscopic techniques, both Raman and Infrared absorption spectroscopy, have significant potential in the field of biomedical analysis, as they can give molecularly specific biochemical information without the use of extrinsic labels and without being invasive or destructive to the system studied. They are routine techniques for fingerprinting and identifying chemicals and act as standard methods in analytical chemistry and pharmacy ${ }^{[1]}$. Both techniques being truly label-free, since the inherent vibrational signature of the biochemistry of the cell or tissue is being observed $^{[2]}$, their potential for diagnostic applications has been well investigated and demonstrated, notably in dermal applications ${ }^{[3-6]}$ but also for many other anatomical sites, including cervix ${ }^{[7,8]}$ skin $^{[9-11]}$, lung ${ }^{[12,13]}$, brain ${ }^{[14]}$, oesophagus ${ }^{[15,16]}$, colon ${ }^{[17]}$, prostate ${ }^{[18]}$, nasopharynx ${ }^{[19]}$, larynx ${ }^{[20]}$, oral ${ }^{[21]}$, breast ${ }^{[22,23]}$ and liver ${ }^{[24]}$. The detailed information of the molecular structure and composition of the tissue provided by Raman and Fourier Transform Infrared absorption (FTIR) spectroscopy ultimately promises an analysis of disease origin and progression. Thus, they offer additional information, potentially valuable for diagnosis, that is not provided by, for example, X-ray or MRI techniques ${ }^{[22]}$. However, although often referred to as complementary techniques, Raman and FTIR spectroscopy are based on very different fundamental physical phenomena, and thus present different relative advantages and disadvantages, and indeed technical challenges to their clinical implementation ${ }^{[25,26]}$. For example, Raman microspectroscopy presents several advantages for the study of live cells, combining molecular analysis with optical imaging. The specific information contained in the Raman spectra can be related to changes to the physiology as a result of external stimuli ${ }^{[27-30]}$. The spatial resolution is of the order of $0.5-2 \mu \mathrm{m}$, providing access to the subcellular organisation of the cells at a molecular 
level ${ }^{[31-35]}$. In the case of FTIR spectroscopy, the spatial resolution is limited to some 5-10 $\mu \mathrm{m}$ in free space applications, although this can be reduced to $1-2 \mu \mathrm{m}$ using high numerical aperture microscopic objectives, as in the case of Attenuated Total Reflection (ATR) FTIR microspectroscopy. The water contribution to the data collected remains a critical difference between the techniques. Whereas dry samples are often required for FTIR analysis of tissue sections, Raman microspectroscopy is perfectly compatible with water immersion measurement which enhances the signal to background ratio and the collection of higher quality data ${ }^{[36,37]}$. The weak contribution from water offers the possibility to study cells in an aqueous environment and thus to keep them alive for the duration of the measurement ${ }^{[2,31,38]}$, whereas the strong absorption from water means that such measurements in infrared can only be performed with high brightness sources such as synchrotrons ${ }^{[39]}$.

Although widely applied to cell and tissue analysis, new challenges are presented by applications of vibrational spectroscopic techniques to bodily fluids, for diagnosis and health monitoring, which would present a less invasive approach than performing biopsies of organs for example during cancer screening ${ }^{[40]}$. In this context, blood serum presents a promising candidate for the application of vibrational spectroscopy. The analysis of the proteins present in the blood stream can potentially deliver crucial information on patient health and indicate the presence of numerous pathologies ${ }^{[41]}$. Blood serum contains $>20,000$ different proteins ranging from 50 g. $\mathrm{L}^{-1}$ (serum albumin) ${ }^{[42,43]}$, to less than 1 ng. $\mathrm{L}^{-1}$ (troponin) ${ }^{[44]}$, with an overall protein concentration of $\sim 1 \mathrm{mM}$. Although other components such as lipids (lipoproteins) can also be found, protein sensing remains the main challenge for diagnostic purposes. The low molecular weight fraction of the serum, referring to by the term "peptidome", is of particular interest for the potentially rich cancer-specific diagnostic information 
it contains. Bound to high-abundance proteins such as albumin, it represents a fingerprint of the molecular events taking place within different organs or tissues related to the presence of cancers but also modification to their close microenvironment ${ }^{[45,46]}$. Therefore, the analysis of protein imbalances in the serum can be directly related to, and indicative of, disease states ${ }^{[47-50]}$. Due to the complex composition of the serum, different tools can be employed for the detection of proteins levels, such as electrophoresis or 2D-SDS-PAGE. The use of monoclonal antibodies can also be useful for detection of small quantities of proteins. Recently, fluorescence based sensing methods using nanoparticles have been developed for more sensitive and cost effective evaluation of proteins levels in the serum ${ }^{[51,52]}$.

The potential of FTIR and Raman spectroscopy has been widely investigated for diagnostic purposes for cell and tissue analysis and the feasibility to use them for serum sensing has been suggested and applied to a wide range of body fluids ${ }^{[53]}$ ranging from serum ${ }^{[54-57]}$, tears ${ }^{[58]}$ urine or saliva ${ }^{[59-61]}$. In both Infrared and Raman spectroscopic studies, to date the analysis has predominantly been performed on air dried drops of serum deposited on spectroscopically neutral substrates such as $\mathrm{CaF}_{2}{ }^{[62 \text {, }}$ 63]. The main reasons is the relatively low concentration of analytes in the serum, leading to poor signal to noise ratios from liquid body fluids (Raman spectroscopy) or the strong contribution of water in the spectra collected (Infrared spectroscopy). Although commonly used, the question of sample homogeneity and measurement reproducibility is of concern. Already highlighted in the literature in the case of serum and tears analysis ${ }^{[58,63,64]}$, the deposition of a drop following by air drying (also referred as drop coating) doesn't necessarily generate a homogenous film of proteins on the substrate. Therefore, the repeatability and accuracy of such studies remains limited, often leading to statistically non relevant results. As drying of the liquid 
samples is accepted as a routine procedure, many efforts have been devoted to the development of robust and complex multivariate analysis methods in order to statistically discriminate the datasets ${ }^{[65,66]}$, rather than improving and adapting the protocols used for sample preparation.

There is a dearth of vibrational spectroscopic studies using liquid samples for in the literature $^{[62,67-69]}$ and limitations due to the presence of water are often quoted in recently published materials ${ }^{[70]}$. Therefore, in the present study, different approaches will be described and proposed as alternatives in order to demonstrate and highlight the feasibility to record high quality data without the requirement for water free samples. The application of vibrational spectroscopy to human serum has been taken as an example, although they are ultimately adaptable to any of the human body fluids. Concentration dependent measurements of solutions of pure biochemical compounds are used to explore the spectral ranges available to both FTIR and Raman spectroscopy as well as the relative sensitivities and detection limits. Sample concentration by centrifugal filtration significantly improves the spectral quality in both spectral modalities, but further improvements can be achieved in Raman spectroscopy by tuning the acquisition protocols, and notably, the spectral integrity in the higher wavenumber region is retained.

\section{Materials and Methods}

\subsection{Sample preparation}

L-proline (Sigma Aldrich, Ireland P4655) and glycine (Sigma Aldrich, Ireland G8898) were first analyzed in the powder form. Additional samples were prepared by dilution in distilled water ranging from $25 \mathrm{mg} / \mathrm{mL}$ up to $300 \mathrm{mg} / \mathrm{mL}$. Gelatin (BDH, 
Ireland, 44045) was also analysed in both the powder form and after dilution in distilled water at concentrations from $10 \mathrm{mg} / \mathrm{mL}-400 \mathrm{mg} / \mathrm{mL}$. Solutions were either analyzed in the liquid form or after deposition on $\mathrm{a} \mathrm{CaF}_{2}$ window, after which they were air dried.

Sterile filtered human serum from normal mixed pool (off the clot) was purchased from TCS Biosciences (Ireland). Samples were prepared either by deposition of $20 \mu \mathrm{L}$ of the serum on a $\mathrm{CaF}_{2}$ window (Crystran Limited, UK) followed by air drying or filtration of $0.5 \mathrm{~mL}$ of the serum using Amicon Ultra- $0.5 \mathrm{ml}$ centrifugal filter devices (Merck, Germany). In the case of centrifugally filtered devices, the 3K device was employed, and $0.5 \mathrm{~mL}$ of the serum was placed in the device and centrifuged at $14,000 \times \mathrm{g}$ for 30 mins. The filtrate is mostly composed of water and molecules smaller than $3 \mathrm{~K}$ molecular weight, while the remainder of the serum (concentrate) is retained in the filter device. The filter device is then placed upside down in a new Eppendorf and spun down at $1000 \mathrm{~g}$ for 2 mins. The resultant is a concentration by a factor of 10 for the remaining serum, with a resultant concentrate volume of $\sim 50 \mu \mathrm{L}$.

\subsection{FTIR Instrumentation}

IR absorption measurements were carried out using a Perkin Elmer Spotlight 400N FTIR imaging system. For comparison, the data have been collected using both the transmission mode and ATR mode.

\subsubsection{Data collection using the transmission mode}

The system is equipped with an AutoImage microscope system operating with a $\mathrm{x} 40$ Cassegrain objective, and can operate in transmission or reflection mode. FTIR data acquired in transmission mode were collected over the nominal free-scanning spectral range with an interferometer speed of $1.0 \mathrm{~cm} / \mathrm{s}$ using a liquid nitrogen cooled mercury 
cadmium telluride (MCT-A) line detector. Spectral measurements were acquired with a pixel size of $25 \mu \mathrm{m} \times 25 \mu \mathrm{m}$ at a spectral resolution of $4 \mathrm{~cm}^{-1}$. Background measurements were acquired on a blank substrate with 120 scans per pixel whereas 8 scans per pixel were recorded from the sample. $20 \mu \mathrm{L}$ of the prepared solution was deposited on a $\mathrm{CaF}_{2}$ window and air dried before recording.

\subsubsection{Data collection using the UATR}

ATR spectra were recorded with the Perkin Elmer Spotlight 400N Universal Attenuated Total Reflectance (UATR) accessory of the spectrometer. In ATR mode, spectral data were the result of 4 scans, with a spectral resolution of $4 \mathrm{~cm}^{-1}$. Either 1 mg of the powder or $20 \mu \mathrm{l}$ of the solution for the different compounds tested was deposited on the crystal for recording. Prior to recording, a background spectrum was recorded and automatically subtracted by the software.

\subsection{Raman spectroscopic measurements}

A Horiba Jobin-Yvon LabRAM HR800 spectrometer was used throughout this work. The spectrometer can be coupled to either an Olympus BX41 upright or an Olympus IX71 inverted microscope. For the measurements, a x60 water immersion objective (LUMPlanF1, Olympus) was employed, providing a spatial resolution of $\sim 1-2 \mu \mathrm{m}$ at the sample with a laser intensity of between $35-40 \mathrm{~mW}$ for each microscope. The confocal hole was set at $100 \mu \mathrm{m}$ for all measurements, the specified setting for confocal operation. The $785 \mathrm{~nm}$ laser line was used in this work, and the system was spectrally calibrated to the $520.7 \mathrm{~cm}^{-1}$ spectral line of silicon.

In the following experiments, the 300 lines/mm grating was used, providing a spectral dispersion of approximately $1.5 \mathrm{~cm}^{-1}$ per pixel with the $785 \mathrm{~nm}$ laser line. The backscattered Raman signal was integrated for 2 x 30 seconds over the spectral range 
from 400 to $1800 \mathrm{~cm}^{-1}$. The detector used was a 16-bit dynamic range Peltier cooled CCD detector.

\section{Results and discussion}

\subsection{Infrared spectroscopy of pure chemicals}

The feasibility of recording infrared spectra from solutions of pure biochemical compounds using FTIR spectroscopy has been evaluated using gelatin (figure 1A), proline and glycine (data not shown) diluted in water at different concentrations. Figure 1A (red spectrum) shows a spectrum recorded from the gelatin powder using the UATR accessory in the range from $2400-4000 \mathrm{~cm}^{-1}$. The spectrum of gelatin is rich in this region, the main features being located at $3281 \mathrm{~cm}^{-1}, 3074 \mathrm{~cm}^{-1}, 2938 \mathrm{~cm}^{-1}$ and $2877 \mathrm{~cm}^{-1}$ (figure 1A: Red spectrum). In aqueous solution, however, these features are swamped by the water contributions (Figure 1A Black) and even at concentrations of $400 \mathrm{mg} / \mathrm{mL}$, which was close to the saturation point of solubility of gelatin in water, no features of the gelatin can be clearly identified (figure 1A Blue).

In the fingerprint region, however, the contributions of water are significantly less, and the features of the gelatin are readily observable. Figure 1B displays spectra obtained from gelatin solutions ranging from $100 \mathrm{mg} / \mathrm{mL}$ up to $400 \mathrm{mg} / \mathrm{mL}$, along with that of pure water. The spectral profiles evolve according to the concentration, especially in the fingerprint region where the specific peaks of the gelatin systematically increase, the best visualization of the spectral profile being reached for the $400 \mathrm{mg} / \mathrm{mL}$ solution.

In this spectral range, the water exhibits only a single feature at $1638 \mathrm{~cm}^{-1}$, overlapping with the amide I band, characteristic of protein rich samples, and also 
partially overlapping with the amide II band region $\left(1580-1490 \mathrm{~cm}^{-1}\right)$. However, when increasing the concentration of the solution, the different features of the gelatin can be seen to systematically evolve. The amide I band appears gradually shifted from 1638 $\mathrm{cm}^{-1}$ to $1630 \mathrm{~cm}^{-1}$ and the amide II band at $1551 \mathrm{~cm}^{-1}$ becomes better defined. Different features can also be seen in the spectral window $1500-1000 \mathrm{~cm}^{-1}$, the main peaks being localised at $1453 \mathrm{~cm}^{-1} 1407 \mathrm{~cm}^{-1} 1,1336 \mathrm{~cm}^{-1}, 1284 \mathrm{~cm}^{-1}, 1246 \mathrm{~cm}^{-1}, 1202$ $\mathrm{cm}^{-1}, 1163 \mathrm{~cm}^{-1}, 1081 \mathrm{~cm}^{-1}$ and $1034 \mathrm{~cm}^{-1}$. The evolution of the features as a function of concentration fits well with a Lambert-Beer like response, as shown in Figure 2 for the case of the integrated areas of the Amide I and Amide II bands. Error margins for the measurements are those of the spectral measurement and the concentration determination, both of the order $\pm 5 \%$. The solid lines show a linear regression fit to the absorbance data. At the lowest concentration measured (100) $\mathrm{mg} / \mathrm{mL}$, water accounts for $\sim 85 \%$ and $\sim 71 \%$ of the absorption in the amide I and amide II regions respectively (dotted horizontal lines). Notably, extrapolation of the regression to the intercept with the water integrated water absorbance for the respective regions indicates a sensitivity of $<10 \mathrm{mg} / \mathrm{mL}$.

\subsection{Infrared spectroscopy of Human serum}

A commonly employed approach to analyzing the composition of biological fluids using FTIR is to deposit a drop of the solution on a suitable substrate such as $\mathrm{CaF}_{2}$ and air dry the sample before collection of spectra in transmission mode ${ }^{[62,63,70,71]}$. The process concentrates the analytes from the solution, potentially allowing better signal to noise, but results in a physically and chemically inhomogeneous sample and, as demonstrated in the previous section, the spectra of the constituent molecular components can be significantly altered in the condensed form. Figure 3 (top) 
presents an infrared transmission image collected from a $20 \mu \mathrm{L}$ drop of human serum after air drying on a $\mathrm{CaF}_{2}$ window. Three examples of spectra taken from different regions of the drop from the inner to the outer region are also displayed. After drying, the serum forms a highly concentrated thin film on the substrate, leading to the saturation in the absorbance read. The maximum absorbance is observed in the center of the deposit. Thus, in order to record infrared spectra from dry serum, a dilution has to be applied. Figure 3 (bottom) presents the infrared image obtained from a dried deposit after dilution of the serum by a factor of 15 using distilled water. After dilution, a ring of highly concentrated proteins is located on the outer part of the deposit. As the central area gives little or no absorbance, it is not usable for chemical characterization. The main limiting aspect of depositing and air drying the serum remains the inhomogeneity of the resulting deposit. The different serum proteins have differing affinities for adsorption onto the substrate surface which results in varying rates of deposition and therefore physical and chemical inhomogeneity in the deposited layer - the so-called Vroman effect. ${ }^{[72]}$ The spectra A, B and C in figure 3 (bottom) illustrate the variation in the spectra collected from the inner, middle and the outer part of the ring. For better visualization, the region $1500-1000 \mathrm{~cm}^{-1}$ has been plotted. The dotted lines indicate shifts in the features, while the arrows highlight a change in the band intensity ratios depending of the location of the spectra. Thus, the use of serum deposited and dried on a substrate will generate variations in the spectral features due to physical and chemical inhomogeneities and, given the uncertainties in the results, is not a satisfactory protocol for diagnostic applications.

However, as demonstrated in section 3.1, the recording of Infrared spectra from aqueous solutions, at least in the fingerprint region, is possible and is thus the best candidate for the study of human serum. As highlighted in figure 1, however, the use 
of highly concentrated solutions is required for infrared spectroscopy in order to reduce the water/protein ratio in the spectra collected, but the fully condensed solid phase results in physically and chemically inhomogeneous samples. Therefore a method of controlled systematic concentration of the serum samples is desirable.

Commercially available, Amicon ultra- 0.5 centrifugal filter devices (Merk) provide, as described by the manufacturer, "a fast ultrafiltration, with the capability for high concentration factors and easy concentrate recovery from the dilute and complex matrices". The centrifugal filter devices can be purchased for different cutoffs (Nominal Molecular Weight Limit ranging from $100 \mathrm{~K}$ to $3 \mathrm{~K}$ ). In the present study, the feasibility to analyse the whole serum was explored, and thus the $3 \mathrm{~K}$ (3000 NMWL) was employed, which means any molecule with a molecular weight higher than $3 \mathrm{~K}$ will be retained in the devices and present in the final concentrate used for spectroscopic analysis. $0.5 \mathrm{~mL}$ of the serum was placed in the device and centrifuged at $14000 \mathrm{x}$ g for $30 \mathrm{mins}$, giving a concentrating factor of 10 with a resultant concentrate volume of $\sim 50 \mu \mathrm{L}$.

After recovery, $20 \mu \mathrm{L}$ of the final concentrate was deposited on the UATR accessory and an infrared spectrum was collected. Figure 4II compares the infrared spectra recorded from human serum using the UATR accessory, in its pristine liquid state (figure 4IIB) and after concentration using centrifugal devices (figure 4IIA). In the pristine liquid state, the signal obtained remains dominated by the water band and only small protein related features are observable. After centrifugal filtration, however, strong features of the serum begin to dominate the spectrum. The major bands are visible at $1637 \mathrm{~cm}^{-1}$ (Amide I band), $1445 \mathrm{~cm}^{-1}, 1452 \mathrm{~cm}^{-1}, 1402 \mathrm{~cm}^{-1}, 1312$ $\mathrm{cm}^{-1}, 1244 \mathrm{~cm}^{-1}, 1170 \mathrm{~cm}^{-1}$ and $1080 \mathrm{~cm}^{-1}$, consistent with observations made on air dried serum, despite the lack of accuracy due to the in-homogeneity in the data 
collected after air drying. An increase of the absorbance of all features (above the level of the water absorbance) by a factor of approximately 5 in the finger print region can be observed. Therefore, the use of centrifugal filter devices can bring new expectations regarding the application of Infrared spectroscopy for the analysis of human serum with the possibility to strongly reduce the water contribution and thus better visualize the presence of the different features related to the complex composition of the serum. However, even at these concentration factors, the spectral range $2800-3700 \mathrm{~cm}^{-1}$ remains dominated by the water features, as shown in figure $4 \mathrm{I}$. The serum recorded after ultrafiltration displays only weak features between 3000$2600 \mathrm{~cm}^{-1}$ (figure 4I red spectrum) and is still dominated by the strong absorbance of the remaining water in the sample (figure 4I spectrum black and blue). Therefore, the main limitation to FTIR spectroscopic analysis of bodily fluids remains the restriction in the accessible spectral range as, although the finger print region remains the most informative regarding the molecular composition of the samples, the high wavenumber spectral range could bring relevant information for more specific chemical characterization.

\subsection{Raman microspectroscopy of pure chemicals}

The relatively weaker signal from water in Raman spectroscopy presents many advantages compared to infrared spectroscopy, especially for the analysis of live cells, which is facilitated by the use of a water immersion objective to be able to collect Raman spectra directly from cells maintained alive in a saline solution or medium ${ }^{[31]}$. However, although the water contribution is weak, it can still contribute over an important part of the final spectrum collected. As seen for Infrared spectroscopy, the Raman spectroscopic technique has a limit of detection for molecules diluted in an 
aqueous solution. As an example, the recent work conducted on 3D collagen gels demonstrated that the fibrous protein forming the gel upon which to grow the cells was still too low in concentration to be detected with Raman spectroscopy ${ }^{[73]}$. The main question is to evaluate the capacity of Raman spectroscopy to record spectra from human serum.

Figure 5I displays examples of spectra recorded from gelatin solutions ranging from $200 \mathrm{mg} / \mathrm{mL}$ to $10 \mathrm{mg} / \mathrm{mL}$ (figure $5 \mathrm{I} \mathrm{B-E}$ ) compared to a spectrum of gelatin recorded from the lyophilized form before preparation of the solution (figure 5IF) and a spectrum of de-ionised water (figure 5IA). As seen for the FTIR analysis, the intensities of the Raman peaks increase systematically with concentration, although notably the Raman spectra are strikingly richer in spectroscopic detail. The spectrum of figure 5IE is very similar to the one obtained from the gelatin powder (figure 5IF), while the gelatin features are significantly diminished in the spectrum collected from the solution at $10 \mathrm{mg} / \mathrm{mL}$ which displays a stronger contribution of the water (figure 5IB).

In Raman spectroscopy, the finger print region between $400-1800 \mathrm{~cm}^{-1}$ is strongly influenced by the presence of a slowly varying, broad background generating an offset of the spectra but also influencing the signal to background ratio and thus the relative band intensity. Thus, the exact evaluation of the water contribution to the final spectra in the region of the amide I band remains difficult. However, the high wavenumber region between $2800-3700 \mathrm{~cm}^{-1}$ is not influenced as strongly by this background and can provide a more precise estimation of the water contribution (figure 5II), which is notably significantly less intense than that observed in FTIR (figure 1). The spectral range $2845-3040 \mathrm{~cm}^{-1}$ exhibits features related to the presence of proteins and lipids in the samples (in the case of gelatin, only protein related) and 
notably, whereas they are swamped by the water absorptions at $400 \mathrm{mg} / \mathrm{mL}$ in FTIR, they are clearly discernible in the Raman spectra of solutions as dilute as $25 \mathrm{mg} / \mathrm{mL}$ (figure 5II red spectrum).

As in the case of FTIR spectra of solutions, a linear dependence of the integrated bands are observed, as shown in Figure 6 for the case of the high wavenumber region $\left(2820 \mathrm{~cm}^{-1}-3020 \mathrm{~cm}^{-1}\right)$, the amide I band $\left(1560 \mathrm{~cm}^{-1}-1715 \mathrm{~cm}^{-1}\right)$ and the region between $1215 \mathrm{~cm}^{-1}-1290 \mathrm{~cm}^{-1}$. Again, error margins for the measurements are those of the spectral measurement and the concentration determination, both of the order $\pm 5 \%$. The solid lines show a linear regression fit to the absorbance data. Notably, in comparison to the FTIR data, at a concentration of $100 \mathrm{mg} / \mathrm{mL}$, the contributions of water to the respective regions are reduced to $44 \%, 64 \%$ and $7 \%$.

Whereas FTIR absorption spectroscopy measures the light absorbed by the sample, Raman spectroscopy measures the light (inelastically) scattered by the sample, and thus significant improvements in signal quality can be achieved by improved signal acquisition protocols. The Raman signal intensity is directly correlated with the amount of backscattered light captured by the objective and redirected to the detector over time. Thus, increasing the acquisition time will induce an increase in the overall spectral intensity but is also accompanied by an improved signal to noise $(\mathrm{S} / \mathrm{N})$ ratio. In order to illustrate this effect, the solution of gelatin at $10 \mathrm{mg} / \mathrm{ml}$ has been recorded using an acquisition time of 150s. Using a spectrum of distilled water as a reference and recorded under the same conditions, it is possible to remove the background present in the spectrum by subtraction to better visualize the gelatin features (figure 5IG). Increased source power can also be used to increase the $\mathrm{S} / \mathrm{N}$ ratio, and therefore, Raman microspectroscopy can potentially detect chemicals present in a solution at 
much lower concentrations compared to FTIR. The use of a more powerful laser source would effectively further reduce the required acquisition time, allowing rapid collection of data from solutions with high signal to noise ratio.

\subsection{Raman microspectroscopy of Human serum}

\subsubsection{Instrumental set up}

Figure 7IC shows a Raman spectrum of human serum recorded in the upright geometry using a x60 objective. Protein like features can be clearly seen above the water background, although in comparison to, for example, the gelatin solution spectrum of figure 5I, the spectral features are relatively poorly defined.

When performing measurements with Raman spectroscopy, different objectives can be employed with different characteristics related to the magnification desired. In order to achieve the highest spatial resolution, the X100 objective can be employed on dry cells or tissue sections. As presented in figure 7II, the sample is usually placed on top of a suitable substrate such as $\mathrm{CaF}_{2}$, allowing to focus the laser on its surface. Using a MplanN objective with a numerical aperture (NA) of 0.9, the working distance is about $0.21 \mathrm{~mm}$. However, when working in immersion using a x60 or x100 water immersion objective with a NA of 1 , the working distance is increased to about $2 \mathrm{~mm}$. Although the recording of Raman spectra from the human serum stock solution can be performed directly by immersing the lens in the solution using the upright microscope (as performed in section 3.3 for gelatin solutions), such an approach can be limited when collecting data from smaller volumes, as in the case of concentrated serum. When deposited on a $\mathrm{CaF}_{2}$ window, the focal point of the laser is outside the drop, as illustrated schematically in figure 7IIB. In order to better analyse 
the serum, the distance between the sample and the objective has to be increased. This is achievable by using an inverted microscope (figure 7IIC). Coupling a thin $\mathrm{CaF}_{2}$ (thickness $0.15 \mathrm{~mm}$ ) to the water immersion objective, the collection of Raman spectra from the serum can be performed. A drop of water is used to reduce the variation in the refractive indexes between the objective, substrate and serum. Notably, as they are outside the focus of the beam, the water drop does not contribute to the spectra collected and only an insignificantly weak signal form the $\mathrm{CaF}_{2}$ can be seen.

Figure 7IB shows a Raman spectrum of human serum stock solution measured using such an inverted geometry. In comparison to the same measurement performed in the inverted geometry, the spectrum is significantly enhanced and the spectral features are considerably better defined.

\subsubsection{Impact of centrifugal filtration}

Figure 7IA presents a spectrum of human serum after filtration using an Amicon ultra-0.5 centrifugal filter device (Merk). As in the case of the FTIR, significant improvements in the sample signal can be achieved by increasing the analyte concentration in the solution using centrifugal filtration, as can be seen by comparison with the spectrum of non-unfiltered serum measured under identical conditions (figure 7IB). The spectrum of figure 7IA exhibits dramatic improvements in the spectral intensities and quality. Moreover, the difference in intensity between the pure deionised water and the spectrum collected from the concentrated serum clearly indicates that minimal contribution from the water occurs with such samples (data not shown). 
The improvements of the Raman spectrum achievable by filtration are equally evident in the high number region, as shown in figure 7III. Spectrum A of 7III has been collected from distilled water as a reference while the spectrum B has been recorded from the serum. The intensity of the band of the water located at $3210 \mathrm{~cm}^{-1}$ is significantly decreased with the apparition of 2 peaks at $2930 \mathrm{~cm}^{-1}$ and $2875 \mathrm{~cm}^{-1}$. After centrifugal filtration, the band of the water is strongly reduced to almost the same intensity of the background, whereas the peaks at $2930 \mathrm{~cm}^{-1}$ and $2875 \mathrm{~cm}^{-1}$ have significantly stronger intensities and an additional peak is clearly discernible at 3060 $\mathrm{cm}^{-1}$ (figure 7IIIC).

\section{Discussion}

The analysis of human serum but also body fluids can be performed using the immersion lens. As for the analysis of live cells, the water immersion objective can be directly dipped into the analyte solution, minimising the intensity loss in the spectra collected by optimizing the optical coupling between the lens and the liquid sample. For measurement of centrifugally filtered serum, the recovery volume is the main limiting factor in such approach. The working distance of the water immersion lens being about $2 \mathrm{~mm}$, the effective thickness of the serum drop after deposition on the $\mathrm{CaF}_{2}$ substrate was found to be too low and also not consistent. The interaction of the concentrate serum with the surface of the substrate varies between samples thus, although the concentrate recovery volume remains quite consistent, the drop size and shape can vary quite considerably.

The use of the inverted geometry improves the reproducibility of the measurements of concentrated serum, which will allow standardization. The size and shape of the drop have little impact on the data collected. The laser being focused on the interface 
between the deposited liquid sample and the $\mathrm{CaF}_{2}$ substrate, as little as $20 \mu \mathrm{L}$ of the concentrated serum can be used for the analysis. Although this work was a proof of concept based on Ultra-0.5 centrifugal filter devices (Merck, Germany) with a Nominal Molecular Weight Limit (NMWL) of $3 \mathrm{~K}$, it is important to point out that many different cut off point are available on the market to specifically separate proteins with high molecular weight. For example, as specified by the manufacturer, centrifugal devices with NMWL of $10 \mathrm{~K}, 30 \mathrm{~K}, 50 \mathrm{~K}$ or $100 \mathrm{~K}$ have higher concentrating capacities but this is also associated with smaller recovery volume in the order of $20 \mu \mathrm{L}$. Such small volumes cannot easily be recorded using the upright set up can be much more readily analysed using an inverted microscope.

Moreover, although in the present study, the human serum is healthy and free of any infection, the ultimate aim is to perform analysis of serum taken from patients for the identification of specific biomarkers for diagnostic purposes. Thus, it is important to design a set up compatible with health and safety legislation. Direct contact between the lens and the serum itself would require appropriate cleaning between measurements. Inverted measurement through a substrate reduces the cleaning and sterilization requirements without worrying about damaging the immersion objective.

Human serum is composed of up to 10,000 proteins, although most are present at very low relative abundances. Serum, derived from plasma with clotting factors removed, contains $60-80 \mathrm{mg}$ of protein $/ \mathrm{mL}$ in addition to various small molecules including salts, lipids, amino acids, and sugars ${ }^{[42]}$. The use of centrifugal filters raises the question of alteration of the serum composition. The NMWL of the devices means any molecules of less than $3000 \mathrm{~g} / \mathrm{mol}$ will be wholly or partially removed from the concentrate which remains in the filter, and are passed through as filtrate. For example, Glucose, with a molecular mass of $180 \mathrm{~g} / \mathrm{mol}$ should be effectively removed 
by centrifugation. Recent studies suggest that low molecular weight (LMW) proteins are particularly interesting for the use of serum for diagnostic applications ${ }^{\text {[74] }}$. Notably, Hands et al ${ }^{[75]}$ have recently demonstrated the use of centrifugal filtration of serum samples for the diagnosis of gliomas using FTIR spectroscopy of the lower molecular weight filtrate $(<10 \mathrm{kDa})$. Although the molecular weight of LMW proteins remains close to the cutoff point of the centrifugal devices used in this work, commercially available devices with lower NMWL can be purchased, retaining molecules with LMW down to 2K. Moreover, although some LMW (low molecular weight) proteins can be filtered out and lost in the process, the use of such filtering devices offers the advantage of removal of undesirable substances from the serum, such as salts and sugars which can potentially spectroscopically interfere with the proteome analysis. As the principal objective of this work was the demonstration of improved measurement protocols rather than in depth analysis of the serum proteome, the 3K Amicon centrifugal devices have been considered suitable. However, for future investigation, the use of lower NMWL devices should be investigated.

Rohleder et al. ${ }^{[62]}$ have undertaken a comparison of FTIR and Raman spectroscopies for the quantitative analysis of human serum, also in relation to other common clinical enzymatic analysis techniques. Multivariate regression was employed to analyse the glucose content in spiked patent samples and root mean square errors of prediction of 14.7 and $17.1 \mathrm{mg} / \mathrm{dl}$ for mid-infrared and Raman spectroscopy, respectively were achieved. The study concluded that the accuracy of current clinical analytical methods is substantially better than that of vibrational spectroscopies and that vibrationalspectroscopy based quantification appears to be limited to accuracies in the 0.1 $\mathrm{mmol} / \mathrm{L}$ range, regardless of the particular choice of the spectroscopic technique. Notably, in this study, samples for FTIR measurement were taken from dried samples 
whereas those for Raman spectroscopy were taken from unfiltered unconcentrated serum.

In the study presented here, it has been demonstrated that FTIR measurements of biochemical species can be made in water solution. Although the high wavenumber region is effectively unusable due to water absorption, clear absorption features are visible in the fingerprint region of gelatin solutions as low as $100 \mathrm{mg} / \mathrm{mL}$. The average molecular mass of gelatin is $\sim 50 \mathrm{~kg} / \mathrm{mol}$, and thus this corresponds to $2 \mathrm{mmol} / \mathrm{L}$. In the case of human serum, concentration by a factor of ten by centrifugal filtration results in a ten fold increase in absorbance of all features in the fingerprint region, although the high wave number region remains obscured by water absorption, even at these elevated concentrations. Critically, the ability to measure human serum in the solution phase at higher concentrations should significantly reduce the measurement predictability, identified by Rohleder et al. ${ }^{[62]}$ as a lower limit on the prediction errors in mid-infrared spectroscopy.

In Raman spectroscopy the interference of water in the spectral signatures of biochemical species is less than for FTIR. In gelatin solutions, clear spectral features are observable at concentrations as low as $10 \mathrm{mg} / \mathrm{mL}$, notably in both the fingerprint and high wavenumber regions. Significant improvements in signal to noise are achievable by prolonged acquisition times, and detailed, high quality spectra of $10 \mathrm{mg} / \mathrm{ml}$ gelatin solutions are achievable after 6-7 minutes, indicating that Raman spectroscopy holds significantly higher potential for applications to analysis of bodily fluids.

In recent years, there has been increased interest in blood serum analysis using Surface Enhanced Raman Spectroscopy (SERS), which can compensate for the low Raman scattering efficiency, especially limiting in the case of liquid samples ${ }^{[76]}$. 
Reported studies applied to blood serum ${ }^{[77]}$ for the detection of gastric ${ }^{[78,79]}$, colorectal $^{[80]}$, pancreatic ${ }^{[81]}$ and naso-pharyngeal cancers ${ }^{[82]}$ highlight the interest and potential of such approaches. However, the use of nano-particles or appropriate metallic based substrates ${ }^{[83]}$ is required, and while the approach is promising, reproducibility in the data collected remains a challenge ${ }^{[84]}$. Moreover, the question of selectivity and sensitivity are questionable, especially in presence of high molecular weight proteins ${ }^{[85]}$.

Therefore, the development of more suitable protocol for Raman microspectrsocopy remains crucial for the analysis of body fluids leading to a better detection of the Raman signatures in liquid samples. Thus, as presented in the present study, for the case of human serum, sample concentration by a factor of 10 by centrifugal filtering dramatically improves the spectral intensity and signal to noise without the requirement of further signal enhancement with nano-particles. Although the standard upright measurement geometry can be employed, reduced background is achievable by measurement in an inverted geometry, using an immersion objective. Enhanced signal intensities allow reduced acquisition times with the promise of high throughput in routine screening applications. Ultimately, in clinical environment, such a geometry has the advantage that it provides improved signal quality through immersion, without the danger or inconvenience of contact of the objective with the sample.

\section{Conclusion}

Although vibrational the spectroscopic techniques of infrared absorption and Raman scattering have been widely explored for diagnostic applications in tissues ex vivo and cellular analysis in vitro, their applications to bodily fluids has largely been limited 
due to weak spectral signatures of the relevant analytes in pristine fluids, and the physical and chemical inhomogeneities of solid deposits. Concentration dependent measurements of pure biochemicals in aqueous solution demonstrates, however, that both methodologies can be employed for sensitive quantitative measurements, although the high wavenumber region the spectral features of the analytes are obscured by those of water in the case of FTIR. In the case of human serum, both FTIR and Raman spectroscopy give relatively weak signals, but the signal to background ratios are considerably enhanced by the used of commercially available devices ultra-0.5 centrifugal filter devices (Merck, Germany) which result in a concentration of the analytes by a factor of $\sim 10$, and a consequent increase in the spectral signatures. Although the high wavenumber region is still obscured by water in the case of FTIR, the full spectral region is dominated by protein features in the case of Raman spectroscopy. Collection efficiency for immersion Raman spectroscopy can be further enhanced by the use of an inverted geometry. Using centrifugal filtration devices to remove of low molecular weight proteins, enhances signals and intrinsic spectral reproducibility. These improved spectral acquisition protocols opens up the potential applications of real clinical applications for spectroscopic analysis of bodily fluids.

\section{Acknowledgements}

This work is published in memory of François Petitjean, who died tragically in March 2013. The research was supported by the National Biophotonics and Imaging Platform (NBIP) Ireland, Higher Education Authority PRTLI (Programme for Research in Third Level Institutions) Cycle 4, co-funded by the Irish Government and 
the European Union Structural Fund and by Science Foundation Ireland under Grant Number 11/PI/08, . 


\section{References}

[1] S. Wartewig, R. H. Neubert, Adv Drug Deliv Rev 57, 1144 (2005)

[2] F. Draux, P. Jeannesson, A. Beljebbar, A. Tfayli, N. Fourre, M. Manfait, J. Sule-Suso, G. D. Sockalingum, Analyst 134, 542 (2009)

[3] P. J. Caspers, G. W. Lucassen, E. A. Carter, H. A. Bruining, G. J. Puppels, J Invest Dermatol 116, 434 (2001)

[4] P. J. Caspers, G. W. Lucassen, R. Wolthuis, H. A. Bruining, G. J. Puppels, Biospectroscopy 4, S31 (1998)

[5] P. Caspers, G. Lucassen, H. Bruining, G. Puppels, Journal of Raman Spectroscopy 31, 813 (2000)

[6] T. S. Bakker, M. Witjes, H. Sterenborg, O. Speelman, J. Roodenburg, E. Marple, H. Bruining, G. Puppels, Anal Chem 72, 6010 (2000)

[7] A. Mahadevan-Jansen, M. F. Mitchell, N. Ramanujam, A. Malpica, S. Thomsen, U. Utzinger, R. Richards-Kortum, Photochem Photobiol 68, 123 (1998)

[8] U. Utzinger, M. Brewer, E. Silva, D. Gershenson, R. C. Blast, Jr., M. Follen, R. Richards-Kortum, Lasers Surg Med 28, 56 (2001)

[9] M. Gniadecka, O. Faurskov Nielsen, D. H. Christensen, H. C. Wulf, J Invest Dermatol 110, 393 (1998)

[10] L. D. Nunes, A. A. Martin, L. Silveira, M. Zampieri, Spectroscopy-an International Journal 17, 597 (2003)

[11] A. Nijssen, T. C. Bakker Schut, F. Heule, P. J. Caspers, D. P. Hayes, M. H. Neumann, G. J. Puppels, J Invest Dermatol 119, 64 (2002)

[12] S. Kaminaka, H. Yamazaki, T. Ito, E. Kohda, H. Hamaguchi, Journal of Raman Spectroscopy Volume 32, 139 (2001)

[13] Z. Huang, A. McWilliams, H. Lui, D. I. McLean, S. Lam, H. Zeng, Int J Cancer 107, 1047 (2003)

[14] A. Mizuno, H. Kitajima, K. Kawauchi, S. Muraishi, Y. Ozaki, Journal of Raman Spectroscopy

25, 25 (1994)

[15] I. A. Boere, D. J. Robinson, H. S. de Bruijn, J. van den Boogert, H. W. Tilanus, H. J. Sterenborg, R. W. de Bruin, Photochem Photobiol 78, 271 (2003)

[16] C. Kendall, N. Stone, N. Shepherd, K. Geboes, B. Warren, R. Bennett, H. Barr, J Pathol 200, 602 (2003)

[17] A. Molckovsky, L. M. Song, M. G. Shim, N. E. Marcon, B. C. Wilson, Gastrointest Endosc 57, 396 (2003)

[18] P. Crow, N. Stone, C. A. Kendall, J. S. Uff, J. A. Farmer, H. Barr, M. P. Wright, Br J Cancer 89, 106 (2003)

[19] D. P. Lau, Z. Huang, H. Lui, C. S. Man, K. Berean, M. D. Morrison, H. Zeng, Lasers Surg Med 32, 210 (2003)

[20] D. P. Lau, Z. Huang, H. Lui, D. W. Anderson, K. Berean, M. D. Morrison, L. Shen, H. Zeng, Lasers Surg Med 37, 192 (2005)

[21] C. M. Krishna, G. D. Sockalingum, J. Kurien, L. Rao, L. Venteo, M. Pluot, M. Manfait, V. B. Kartha, Appl Spectrosc 58, 1128 (2004)

[22] C. J. Frank, R. L. McCreery, D. C. Redd, Anal Chem 67, 777 (1995)

[23] K. E. Shafer-Peltier, A. S. Haka, M. Fitzmaurice, J. Crowe, J. Myles, R. R. Dasari, M. S. Feld, Journal of Raman Spectroscopy 33, 552 (2002) 
[24] S. R. Hawi, W. B. Campbell, A. Kajdacsy-Balla, R. Murphy, F. Adar, K. Nithipatikom, Cancer Lett 110, 35 (1996)

[25] S. M. Ali, F. Bonnier, H. Lambkin, K. Flynn, V. McDonagh, C. Healy, T. C. Lee, F. M. Lyng, H. J. Byrne, Analytical Methods 5, 2281 (2013)

[26] Hugh J. Byrne, Ganesh D. Sockalingum, Nick Stone, in D. Moss,"Biomedical Applications of Synchrotron Infrared Microspectroscopy: A Practical Approach”, Vol. No. 11,(RSC Analytical Spectroscopy Monographs, 2011).

[27] I. Notingher, L. L. Hench, Expert Rev Med Devices 3, 215 (2006)

[28] I. Notingher, S. Verrier, S. Haque, J. M. Polak, L. L. Hench, Biopolymers 72, 230 (2003)

[29] H. Nawaz, F. Bonnier, P. Knief, O. Howe, F. M. Lyng, A. D. Meade, H. J. Byrne, Analyst 135, 3070 (2010)

[30] H. Nawaz, F. Bonnier, A. D. Meade, F. M. Lyng, H. J. Byrne, Analyst 136, $2450(2011)$

[31] F. Bonnier, P. Knief, B. Lim, A. D. Meade, J. Dorney, K. Bhattacharya, F. M. Lyng, H. J. Byrne, Analyst 135, 3169 (2010)

[32] J. Dorney, F. Bonnier, A. Garcia, A. Casey, G. Chambers, H. J. Byrne, Analyst 137, 1111 (2012)

[33] G. J. Puppels, H. S. Garritsen, G. M. Segers-Nolten, F. F. de Mul, J. Greve, Biophys J 60, 1046 (1991)

[34] C. Matthaus, T. Chernenko, J. A. Newmark, C. M. Warner, M. Diem, Biophys J 93, 668 (2007)

[35] M. Miljkovic, T. Chernenko, M. J. Romeo, B. Bird, C. Matthaus, M. Diem, Analyst 135, 2002 (2010)

[36] F. Bonnier, S. M. Ali, P. Knief, H. Lambkin, K. Flynn, V. McDonagh, C. Healy, T. C. Lee, F. M. Lyng, H. J. Byrne, Vibrational Spectroscopy 61, 124 (2012)

[37] F. Bonnier, A. Mehmood, P. Knief, A. D. Meade, W. Hornebeck, H. Lambkin, K. Flynn, V. McDonagh, C. Healy, T. C. Lee, F. M. Lyng, H. J. Byrne, Journal of Raman Spectroscopy 42, 888 (2011)

[38] F. Bonnier, A. D. Meade, S. Merzha, P. Knief, K. Bhattacharya, F. M. Lyng, H. J. Byrne, Analyst 135, 1697 (2010)

[39] D. R. Whelan, K. R. Bambery, L. Puskar, D. McNaughton, B. R. Wood, Analyst 138, 3891 (2013)

[40] D. M. Good, V. Thongboonkerd, J. Novak, J. L. Bascands, J. P. Schanstra, J. J. Coon, A. Dominiczak, H. Mischak, J Proteome Res 6, 4549 (2007)

[41] S. Hu, J. A. Loo, D. T. Wong, Proteomics 6, 6326 (2006)

[42] J. N. Adkins, S. M. Varnum, K. J. Auberry, R. J. Moore, N. H. Angell, R. D. Smith, D. L. Springer, J. G. Pounds, Mol Cell Proteomics 1, 947 (2002)

[43] R. Pieper, C. L. Gatlin, A. J. Makusky, P. S. Russo, C. R. Schatz, S. S. Miller, Q. Su, A. M. McGrath, M. A. Estock, P. P. Parmar, M. Zhao, S. T. Huang, J. Zhou, F. Wang, R. Esquer-Blasco, N. L. Anderson, J. Taylor, S. Steiner, Proteomics 3, 1345 (2003)

[44] E. M. Antman, M. J. Tanasijevic, B. Thompson, M. Schactman, C. H. McCabe, C. P. Cannon, G. A. Fischer, A. Y. Fung, C. Thompson, D. Wybenga, E. Braunwald, N Engl J Med 335, 1342 (1996)

[45] L. A. Liotta, E. F. Petricoin, J Clin Invest 116, 26 (2006)

[46] E. F. Petricoin, C. Belluco, R. P. Araujo, L. A. Liotta, Nat Rev Cancer 6, 961 (2006) 
[47] L. Thadikkaran, M. A. Siegenthaler, D. Crettaz, P. A. Queloz, P. Schneider, J. D. Tissot, Proteomics 5, 3019 (2005)

[48] A. H. Zhang, H. Sun, G. L. Yan, Y. Han, X. J. Wang, Appl Biochem Biotechnol 170, 774 (2013)

[49] S. Ray, P. J. Reddy, R. Jain, K. Gollapalli, A. Moiyadi, S. Srivastava, Proteomics 11, 2139 (2011)

[50] R. Apweiler, C. Aslanidis, T. Deufel, A. Gerstner, J. Hansen, D. Hochstrasser, R. Kellner, M. Kubicek, F. Lottspeich, E. Maser, H. W. Mewes, H. E. Meyer, S. Mullner, W. Mutter, M. Neumaier, P. Nollau, H. G. Nothwang, F. Ponten, A. Radbruch, K. Reinert, G. Rothe, H. Stockinger, A. Tarnok, M. J. Taussig, A. Thiel, J. Thiery, M. Ueffing, G. Valet, J. Vandekerckhove, W. Verhuven, C. Wagener, O. Wagner, G. Schmitz, Clin Chem Lab Med 47, 724 (2009)

[51] K. Welser, R. Adsley, B. M. Moore, W. C. Chan, J. W. Aylott, Analyst 136, 29 (2011)

[52] M. De, S. Rana, H. Akpinar, O. R. Miranda, R. R. Arvizo, U. H. Bunz, V. M. Rotello, Nat Chem 1, 461 (2009)

[53] R. A. Shaw, H. H. Mantsch, in R. A. Meyers,Encyclopedia of Analytical Chemistry,(John Wiley \& Sons, Chichester, 2006).

[54] M. Huleihel, M. Karpasas, M. Talyshansky, Y. Souprun, Y. Doubijanski, V. Erukhimovitch, Spectroscopy 19101 (2005)

[55] J. L. Pichardo-Molina, C. Frausto-Reyes, O. Barbosa-Garcia, R. HuertaFranco, J. L. Gonzalez-Trujillo, C. A. Ramirez-Alvarado, G. Gutierrez-Juarez, C. Medina-Gutierrez, Lasers Med Sci 22, 229 (2007)

[56] A. T. Harris, A. Lungari, C. J. Needham, S. L. Smith, M. A. Lones, S. E. Fisher, X. B. Yang, N. Cooper, J. Kirkham, D. A. Smith, D. P. Martin-Hirsch, A. S. High, Head Neck Oncol 1, 34 (2009)

[57] J. Backhaus, R. Mueller, N. Formanski, N. Szlama, H.-G. Meerpohl, M. Eidt, P. Bugert, Vibrational Spectroscopy 52173 (2010)

[58] C.-C. Lin, M. M.-T. Kuo, H.-C. Chang, Journal of Medical and Biological Engineering, 30, 343 (2010)

[59] D. A. Scott, D. E. Renaud, S. Krishnasamy, P. Meric, N. Buduneli, S. Cetinkalp, K. Z. Liu, Diabetol Metab Syndr 2, 48 (2010)

[60] J. A. Bispo, E. E. de Sousa Vieira, L. Silveira, A. B. Fernandes, J Biomed Opt 18, 87004 (2013)

[61] S. K. H. Khalil, M. A. Azooz, Journal of Applied Sciences Research, 3, 387 (2007)

[62] D. Rohleder, G. Kocherscheidt, K. Gerber, W. Kiefer, W. Kohler, J. Mocks, W. Petrich, J Biomed Opt 10, 031108 (2005)

[63] K. W. Poon, F. M. Lyng, P. Knief, O. Howe, A. D. Meade, J. F. Curtin, H. J. Byrne, J. Vaughan, Analyst 137, 1807 (2012)

[64] J. Filik, N. Stone, Anal Chim Acta 616, 177 (2008)

[65] K. Gajjar, J. Trevisan, G. Owens, P. Keating, N. Wood, H. Stringfellow, P. Martin-Hirsch, F. Martin, Analyst 138, 3917 (2013)

[66] S. S. S. J. Ahmed, W. Santosh, S. Kumar, T. H. T. Christlet, Vibrational Spectroscopy 53181 (2010)

[67] A. Sahu, S. Sawant, H. Mamgain, C. M. Krishna, Analyst 138, 4161 (2013)

[68] D. Rohleder, W. Kiefer, W. Petrich, Analyst 129, 906 (2004)

[69] H. Fabian, P. Lasch, D. Naumann, J Biomed Opt 10, 031103 (2005)

[70] J. Ollesch, S. L. Drees, H. M. Heise, T. Behrens, T. Bruning, K. Gerwert, Analyst (2013) 
[71] W. Petrich, B. Dolenko, J. Fruh, M. Ganz, H. Greger, S. Jacob, F. Keller, A. E. Nikulin, M. Otto, O. Quarder, R. L. Somorjai, A. Staib, G. Werner, H. Wielinger, Appl Opt 39, 3372 (2000)

[72] L. Vroman, A. L. Adams, G. C. Fischer, P. C. Munoz, Blood 55, 156 (1980)

[73] F. Bonnier, P. Knief, A. D. M. , J. Dorney, K. Bhattacharya, F. M. Lyng, H. J. Byrne, in Clinical and Biomedical Spectroscopy and Imaging II,

Proc. of SPIE-OSA Biomedical Optics, Vol. SPIE Vol. 8087, $80870 F$ (Eds.: Nirmala Ramanujam, J. Popp), Munich, 2011.

[74] R. S. Tirumalai, K. C. Chan, D. A. Prieto, H. J. Issaq, T. P. Conrads, T. D. Veenstra, Mol Cell Proteomics 2, 1096 (2003)

[75] J. R. Hands, P. Abel, K. Ashton, T. Dawson, C. Davis, R. W. Lea, A. J. McIntosh, M. J. Baker, Anal Bioanal Chem (2013)

[76] M. Vendrell, K. K. Maiti, K. Dhaliwal, Y.-T. Chang, Trends in Biotechnology 31, 249 (2013)

[77] W. R. Premasiri, J. C. Lee, L. D. Ziegler, J Phys Chem B 116, 9376 (2012)

[78] J. Lin, R. Chen, S. Feng, J. Pan, Y. Li, G. Chen, M. Cheng, Z. Huang, Y. Yu, H. Zeng, Nanomedicine: Nanotechnology, Biology, and Medicine

7, $655(2011)$

[79] S. Feng, R. Chen, J. Lin, J. Pan, Y. Wu, Y. Li, J. Chen, H. Zeng, Biosens Bioelectron 26, 3167 (2011)

[80] D. Lin, S. Feng, J. Pan, Y. Chen, J. Lin, G. Chen, S. Xie, H. Zeng, R. Chen, Opt Express 19, 13565 (2011)

[81] X. Wang, X. Qian, J. J. Beitler, Z. G. Chen, F. R. Khuri, M. M. Lewis, H. J. Shin, S. Nie, D. M. Shin, Cancer Res 71, 1526 (2011)

[82] S. Feng, R. Chen, J. Lin, J. Pan, G. Chen, Y. Li, M. Cheng, Z. Huang, J. Chen, H. Zeng, Biosens Bioelectron 25, 2414 (2010)

[83] B. Sharma, R. R. Frontiera, A.-I. Henry, E. Ringe, R. P. V. Duyne, Materials Today 15, 16 (2012)

[84] L. Rodriguez-Lorenzo, L. Fabris, R. A. Alvarez-Puebla, Anal Chim Acta 745, $10(2012)$

[85] X. X. Han, Y. Ozaki, Trends in Analytical Chemistry 38, 67 (2012) 


\section{Figure legends}

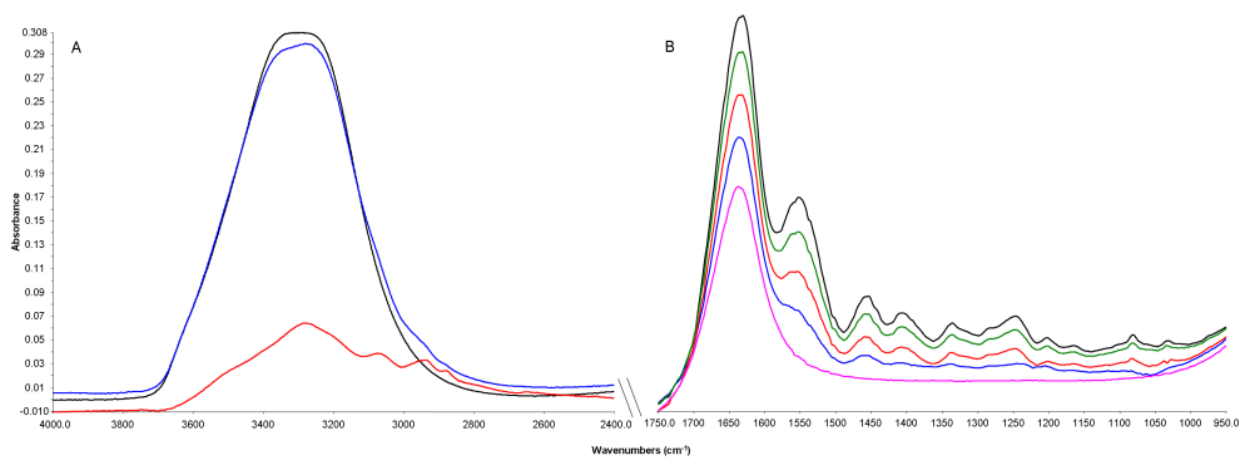

Figure 1: Example of spectra recorded using the UATR accessory of the Perkin Elmer Spotlight 400N. A: high wavenumber region from water (black); gelatin at 400 $\mathrm{mg} / \mathrm{mL}$ (blue) and gelatin powder (Red). B: finger print region from gelatin solutions at a concentration of $100 \mathrm{mg} / \mathrm{mL}$ (blue), $200 \mathrm{mg} / \mathrm{mL}$ (red), $300 \mathrm{mg} / \mathrm{mL}$ (green) and $400 \mathrm{mg} / \mathrm{mL}$ (black). For comparison, a spectrum of distilled water has been added (pink) No offset or correction has been applied.

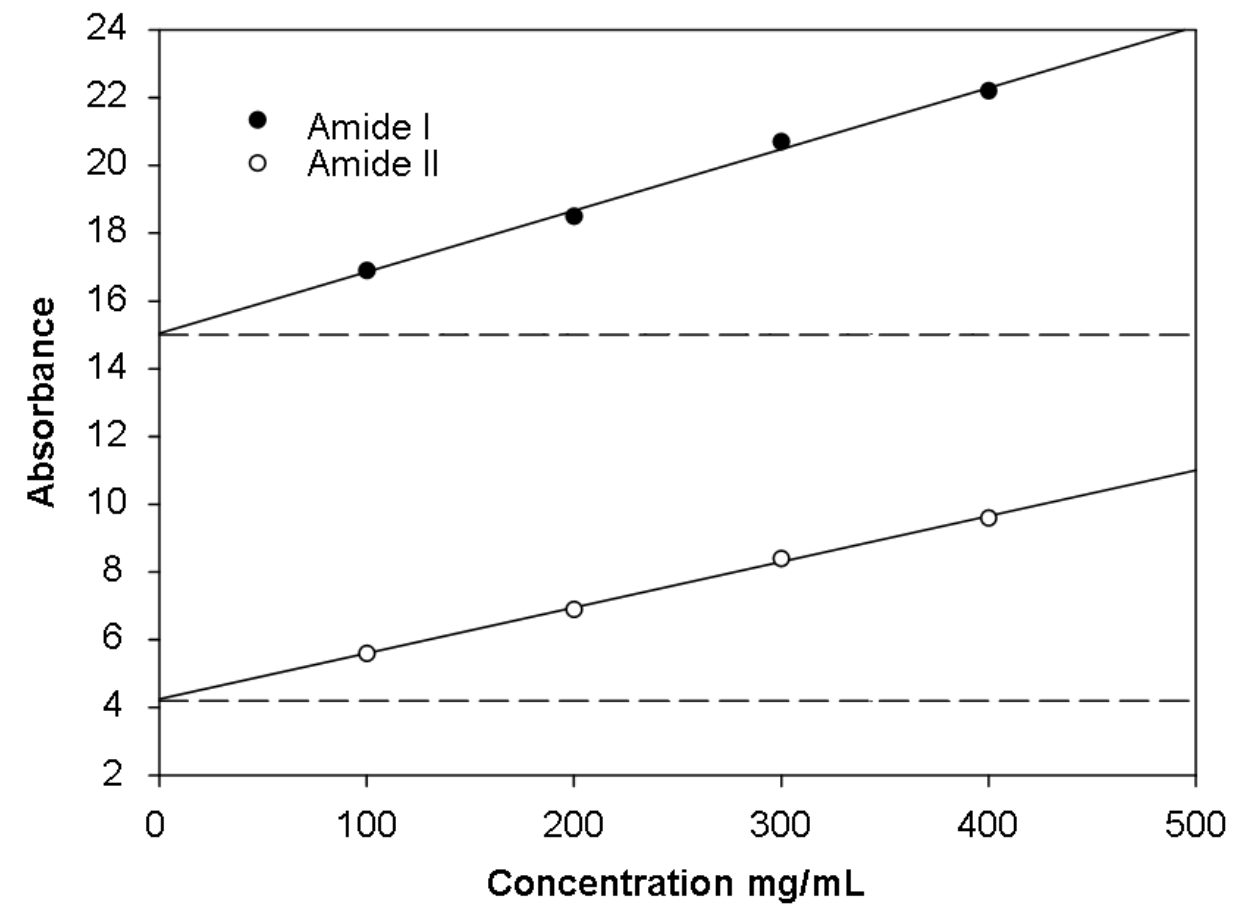


Figure 2: A: Area under the Amide I band (1740-1580 $\left.\mathrm{cm}^{-1}\right)$ and B: Area under the Amide II band (1580-1500 $\left.\mathrm{cm}^{-1}\right)$. The dotted lines are the respective integrated intensities recorded from de-ionised water.
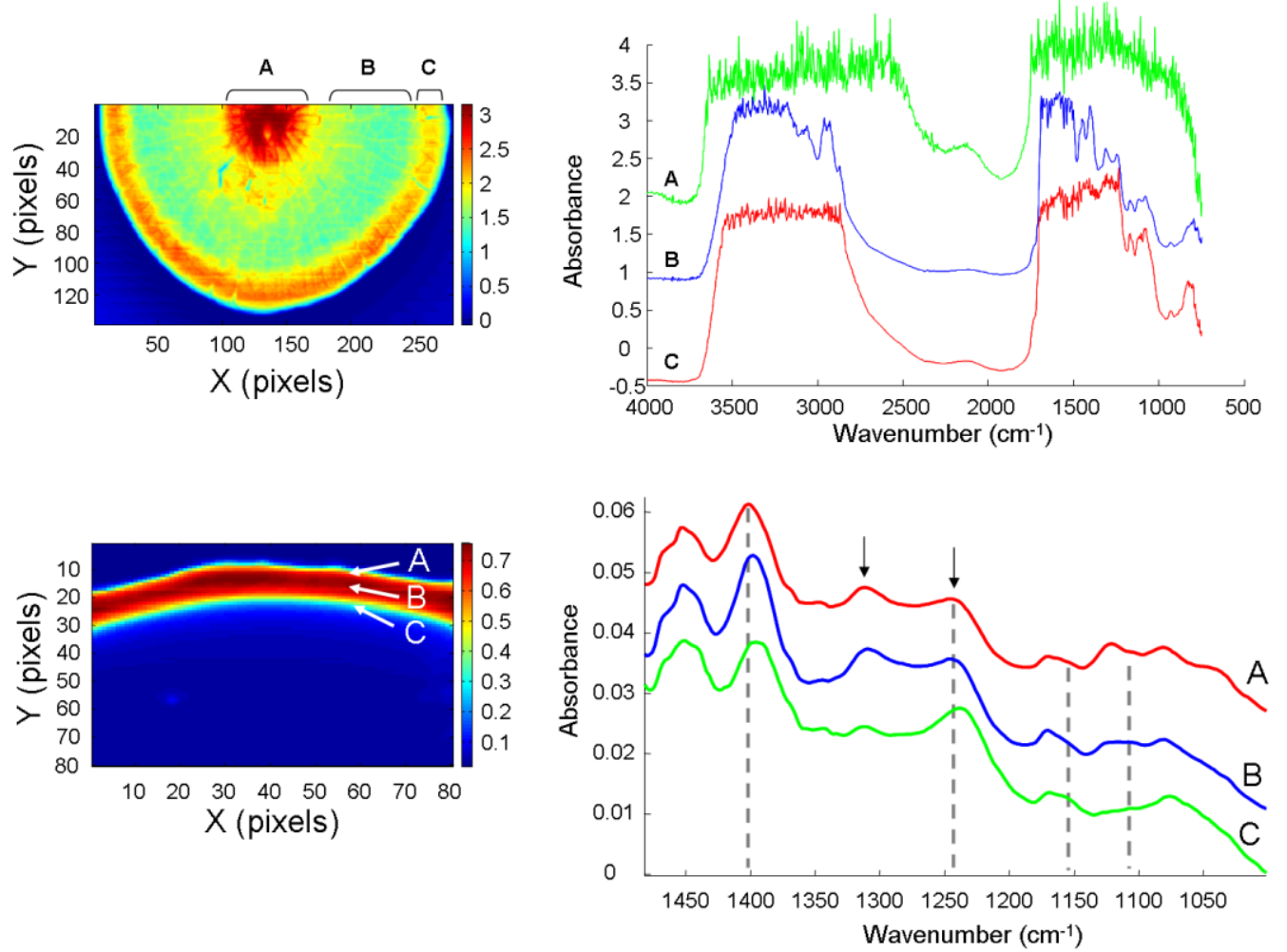

Figure 3: Top: Infrared transmission image collected from a $20 \mu 1$ drop of human serum after air drying with the corresponding spectra extracted from the labeled regions A, B and C. Bottom: Infrared image collected for a $20 \mu \mathrm{l}$ drop of human serum diluted 1/15 after air drying. Spectra collected in the region A, B and C are also presented. The spectra have been baseline corrected and vector normalised. 


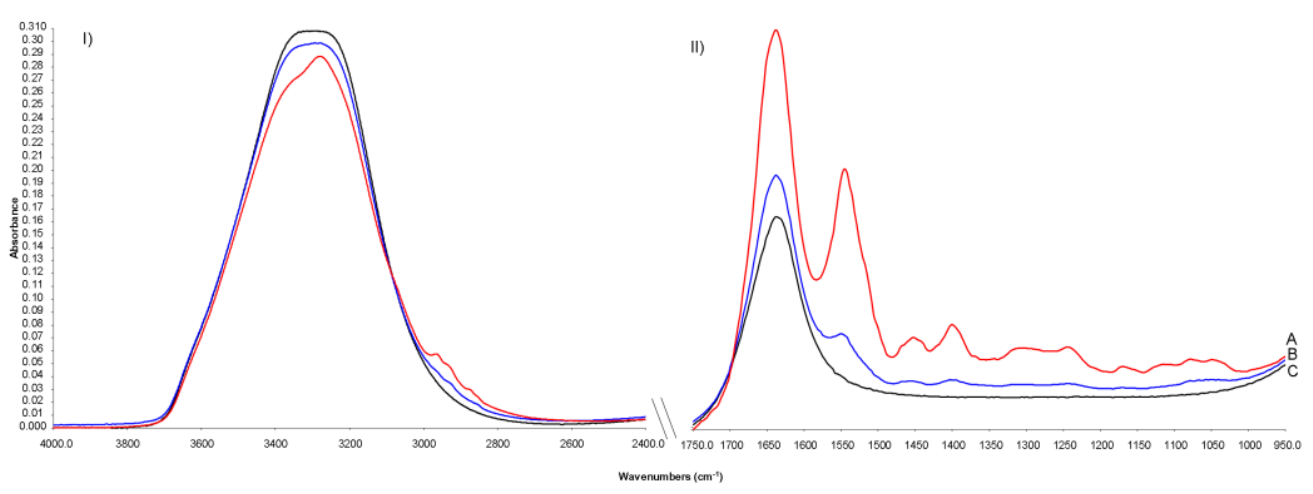

Figure 4: Infrared spectra recorded using the UATR accessory of the Perkin Elmer Spotlight 400N. I: Black: infrared spectra from distilled water; Blue: Infrared spectra from human serum; Red: Infrared spectra from human serum after centrifugal filtration. II: A: Infrared spectrum from human serum after centrifugal filtration; B: Infrared spectrum from human serum; C: infrared spectra from distilled water; No offset or corrections have been applied to the spectra.

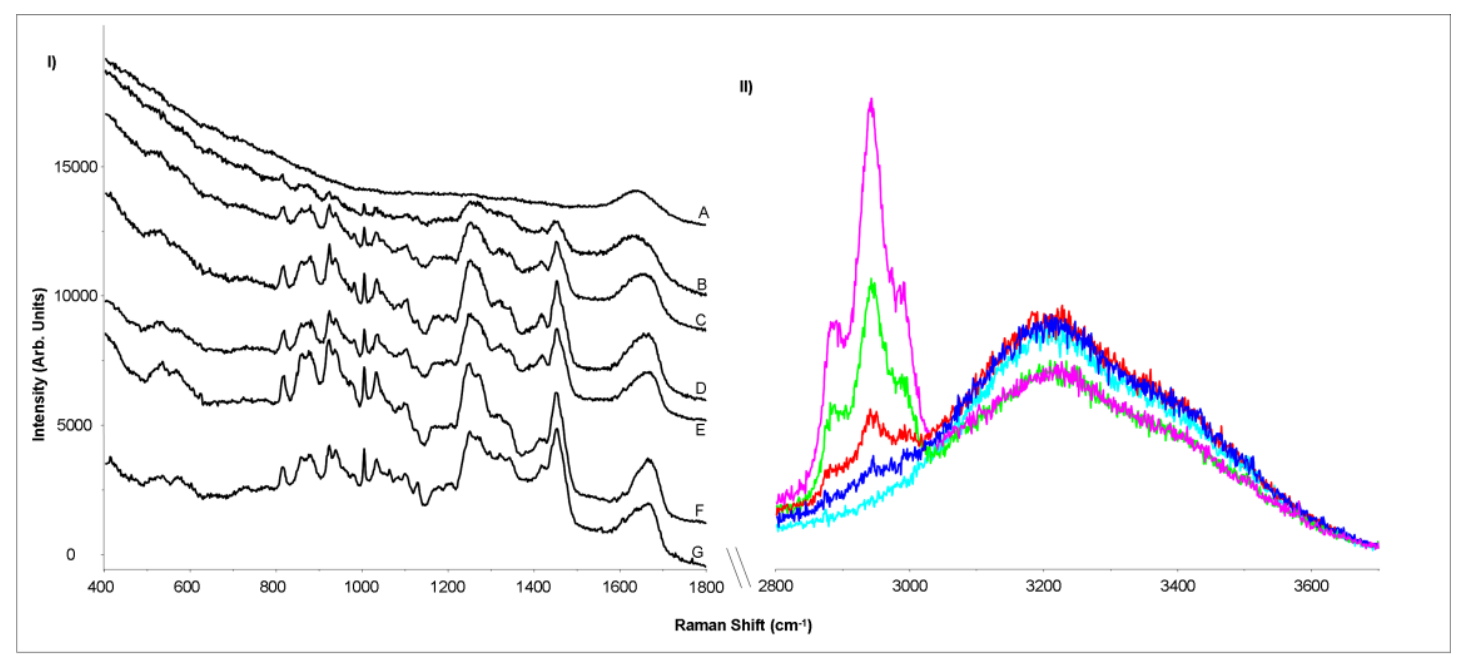

Figure 5 I: Spectra recorded using the $785 \mathrm{~nm}$ laser line. A: deionised water; B: gelatin $10 \mathrm{mg} / \mathrm{mL}$; C: gelatin $25 \mathrm{mg} / \mathrm{mL}$, D: gelatin $100 \mathrm{mg} / \mathrm{mL}$ E: gelatin 200 $\mathrm{mg} / \mathrm{mL}$, F: Lyophilized gelatin and G: gelatin $10 \mathrm{mg} / \mathrm{mL}(2 \times 150 \mathrm{~s}-60 \mathrm{x}$ water immersion objective) after water subtraction (intensity $\mathrm{x} 8$ for comparison). Spectra have been offset for clarity. II: Raman spectra recorded in the high wavenumber region of gelatin solutions at a concentration of $200 \mathrm{mg} / \mathrm{mL}$ (pink), $100 \mathrm{mg} / \mathrm{mL}$ (green), $25 \mathrm{mg} / \mathrm{mL}$ (red) and $10 \mathrm{mg} / \mathrm{mL}$ (blue). For comparison, a spectrum of distilled water has been added (light blue) No offset or correction has been applied. 


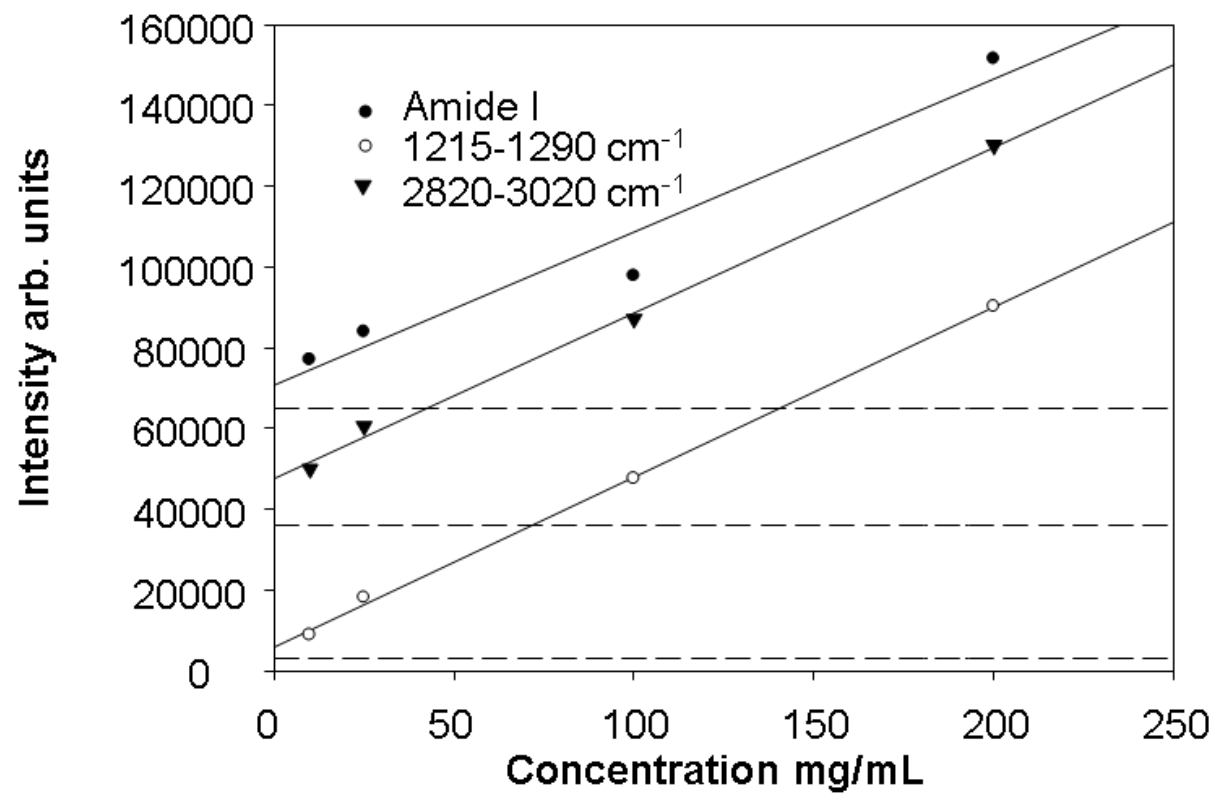

Figure 6: Area under the curve of the protein features in the high wavenumber region $\left(2820 \mathrm{~cm}^{-1}-3020 \mathrm{~cm}^{-1}\right)$, the amide I band, and the region between $1215 \mathrm{~cm}^{-1}-1290 \mathrm{~cm}^{-1}$ of gelatin solutions at a concentration of $200 \mathrm{mg} / \mathrm{mL}$ ), $100 \mathrm{mg} / \mathrm{mL}, 25 \mathrm{mg} / \mathrm{mL}$ and 10 $\mathrm{mg} / \mathrm{mL}$. The dotted lines represent the integrated baseline contributions of pure water in each frequency region. 


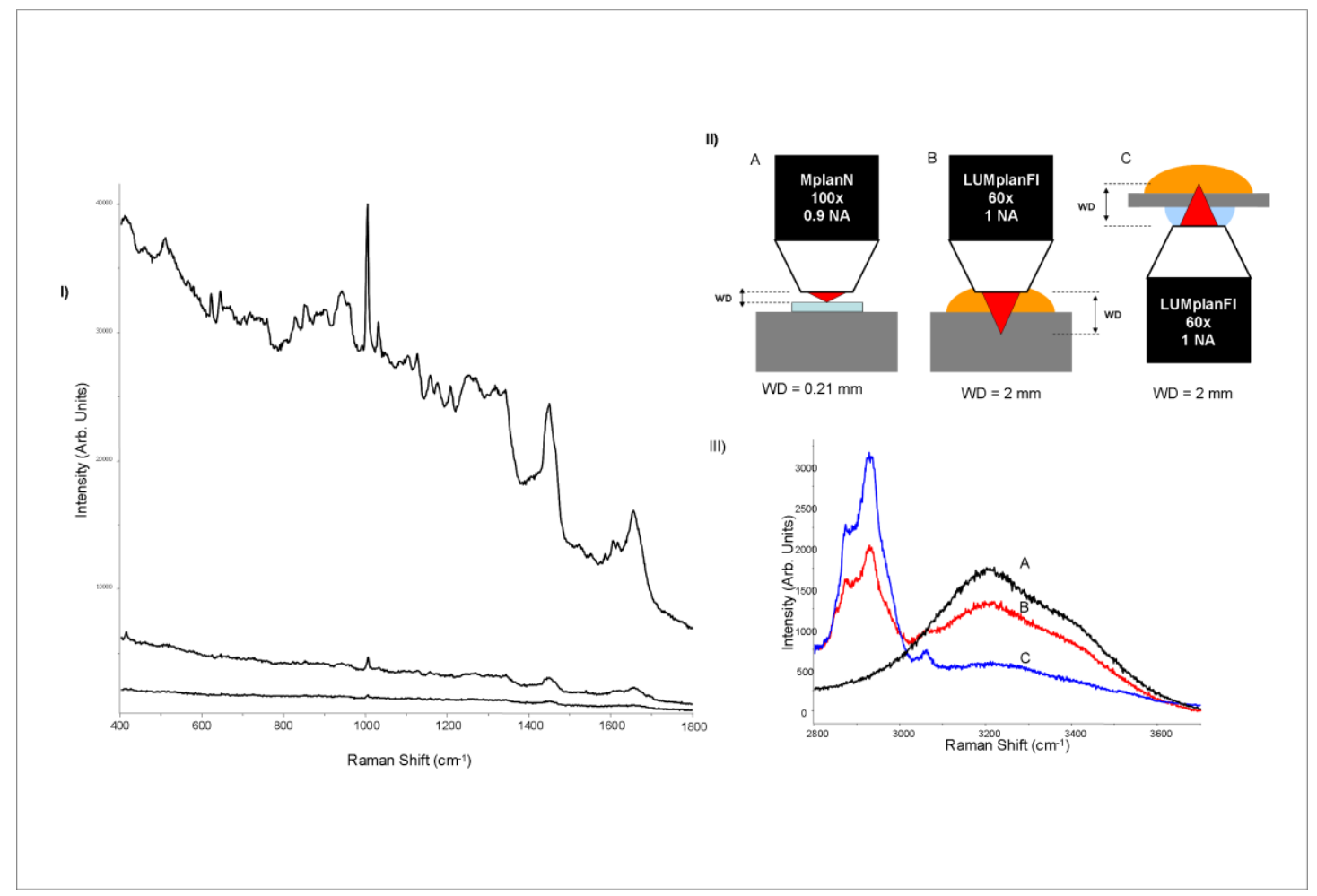

Figure 7: Raman spectra recorded from human serum using Labram HR 800. I: Using the inverted set up after centrifugal filtration; B: In the standard upright position using a X60 immersion objective and $\mathbf{C}$ : Using the inverted microscope couple to the immersion X60 objective. II: Examples of different settings used for the analysis of human serum using Labram HR 800. A: in the standard upright position; B: In the standard upright position using a X60 immersion objective and $\mathbf{C}$ : Using the inverted microscope couple to the immersion X60 objective. III: A: Raman spectrum recorded using the inverted set up from distilled water; B: Raman spectrum recorded from the Human serum; C: Raman spectrum recorded from the Human serum after ultrafiltration using the Amicon ultra- 0.5 centrigugal filter devices $3 \mathrm{~K}$. No offset or correction has been applied. 